\title{
Pemafibrate (K-877), a novel selective peroxisome proliferator-activated receptor alpha modulator for management of atherogenic dyslipidaemia
}

\author{
Jean-Charles Fruchart ${ }^{*}$
}

\begin{abstract}
Despite best evidence-based treatment including statins, residual cardiovascular risk poses a major challenge for clinicians in the twenty first century. Atherogenic dyslipidaemia, in particular elevated triglycerides, a marker for increased triglyceride-rich lipoproteins and their remnants, is an important contributor to lipid-related residual risk, especially in insulin resistant conditions such as type 2 diabetes mellitus. Current therapeutic options include peroxisome proliferator-activated receptor alpha (PPARa) agonists, (fibrates), but these have low potency and limited selectivity for PPARa. Modulating the unique receptor-cofactor binding profile to identify the most potent molecules that induce PPARa-mediated beneficial effects, while at the same time avoiding unwanted side effects, offers a new therapeutic approach and provides the rationale for development of pemafibrate (K-877, Parmodia $^{\mathrm{TM}}$ ), a novel selective PPARa modulator (SPPARMa). In clinical trials, pemafibrate either as monotherapy or as add-on to statin therapy was effective in managing atherogenic dyslipidaemia, with marked reduction of triglycerides, remnant cholesterol and apolipoprotein CIII. Pemafibrate also increased serum fibroblast growth factor 21, implicated in metabolic homeostasis. There were no clinically meaningful adverse effects on hepatic or renal function, including no relevant serum creatinine elevation. A major outcomes study, PROMINENT, will provide definitive evaluation of the role of pemafibrate for management of residual cardiovascular risk in type 2 diabetes patients with atherogenic dyslipidaemia despite statin therapy.
\end{abstract}

Keywords: Peroxisome proliferator-activated receptor alpha, SPPARM, K-877, Pemafibrate, Fibrates, Residual cardiovascular risk, Triglycerides, Atherogenic dyslipidaemia

\section{Background}

Preventing cardiovascular disease (CVD) is a key challenge facing clinicians world-wide this century. Despite improvement in CVD mortality in developed regions, low to middle-income countries have a growing burden of CVD mortality and disability, driven by increasing rates of obesity, diabetes and dyslipidaemia [1-3]. Indeed, with the exception of the USA, the top 10 countries for diabetes prevalence in 2040 will be emerging economies, led by China and India [4]. Consequently, much of the future societal burden of CVD, estimated to exceed one

*Correspondence: jean-charles.fruchart@r3i.org

R3i Foundation, St. Alban-Anlage 46, Basel, Switzerland trillion dollars by 2030 [5], will be in regions which can ill afford such costs.

Low-density lipoprotein cholesterol (LDL-C) is undoubtedly the primary priority for lipid management to prevent CVD [6, 7]. Statins, the cornerstone of LDL-C lowering therapy, have proven efficacy in reducing the risk of a CVD event by $20-30 \%$, but still leave a high residual cardiovascular risk [8]. In part, this may be reduced by further lowering of LDL-C with nonstatin therapy, as shown by the Examining Outcomes in Subjects With Acute Coronary Syndrome: Vytorin Ezetimibe/Simvastatin) vs Simvastatin (IMPROVE-IT) trial with ezetimibe [9], and the Further Cardiovascular Outcomes Research With PCSK9 Inhibition in Subjects 
With Elevated Risk (FOURIER) trial with evolocumab [10]; however, there is also the need to consider other lipid abnormalities. A growing body of evidence highlights the relevance of atherogenic dyslipidaemia, characterised by increased triglyceride (TG)-rich lipoproteins and their remnants (for which elevated TGs are a metric), often with subnormal plasma concentrations of highdensity lipoprotein cholesterol (HDL-C), and an increase in small dense LDL particle numbers, typically seen in insulin resistant conditions such as type 2 diabetes mellitus, as a contributor to lipid-related residual cardiovascular risk, as well as the risk of silent coronary artery disease [11-13]. Overproduction of very low-density lipoproteins (VLDL), with increased secretion of TGs and apolipoprotein (apo) B100, appears to be a key driver of this dyslipidaemia.

Inhibition of cholesteryl ester transfer protein (CETP), which mediates the heteroexchange of triglycerides from VLDL or LDL and cholesteryl esters from HDL, was considered a possible therapeutic approach. However, the first three CETP inhibitors had either safety issues (torcetrapib) or no effect on clinical cardiovascular outcomes in high-risk patients (dalcetrapib, evacetrapib) [14-16]. The last of these agents, anacetrapib, was very recently shown to have a modest albeit statistically significant benefit over 4 years in the Randomized EValuation of the Effects of Anacetrapib Through Lipid-modification (REVEAL) trial, although the role of HDL-raising in this outcome remains a matter for scientific conjecture [17]. There has also been a renewed focus on the management of elevated TGs and remnant cholesterol (the cholesterol contained in TG-rich lipoproteins). Support for the atherogenicity of remnant cholesterol is based on the totality of evidence from observational studies showing an association between elevated remnant cholesterol and ischaemic heart disease, as well as genetic insights which show that remnant cholesterol is causal for ischaemic heart disease independent of HDL-C [18, 19]. Most recently, remnant cholesterol has been implicated as a contributor to the increased CVD risk associated with obesity [20]. These findings have prompted a rethink of the role of lipid targets beyond LDL-C, with for example, the American Diabetes Association recommending TG-lowering as an important secondary target in patients with diabetes [21]. It should be noted, however, that for isolated severe hypertriglyceridaemia, intervention is indicated due to pancreatitis risk not for prevention of CVD [22].

With growing recognition of the importance of targeting atherogenic dyslipidaemia comes a re-evaluation of available therapeutic options. Fibrates, peroxisome proliferator-activated receptor (PPAR) $\alpha$ agonists, are the most logical option as an add-on to statin therapy for management of elevated TGs and atherogenic dyslipidaemia, typically associated with insulin resistant conditions [7,23]. While evidence in both primary and secondary prevention settings is supportive of their use [24, 25], the lack of a definitive mortality benefit has led many clinicians to view these agents as 'second choice'. Despite this, there is support from subgroup analyses of the major fibrate trials that targeting these treatments to patients with atherogenic dyslipidaemia significantly reduces CVD risk (with or without statin treatment) [26]; the ACCORDION study, involving passive extended follow-up of the Action to Control Cardiovascular Risk in Diabetes (ACCORD) study, showed that this benefit persisted over the long-term [27]. Additionally, the Bezafibrate Infarction Prevention (BIP) study showed long-term benefit in reducing mortality, more so in individuals with baseline hypertriglyceridaemia [28].

With escalating rates of diabetes, obesity and CVD, especially in developing regions, management of atherogenic dyslipidaemia, as well as metabolic abnormalities and chronic inflammation typically associated with these conditions, is now a priority for reducing residual cardiovascular risk. This scenario highlights the need for new therapeutic options. Selective PPAR $\alpha$ modulatorsSPPARM $\alpha$ agents-could well provide one approach to resolving this challenge, and offer a more accessible therapeutic approach to managing this dyslipidaemia [29].

\section{Search strategy}

This review describes the profile of a novel SPPARM $\alpha$, determined using a search methodology as follows. The literature was searched using Medline, Current Contents, PubMed, and relevant references with the terms 'residual cardiovascular risk', 'peroxisome proliferator-activated receptor,' 'pemafibrate,' 'K-877', 'atherogenic dyslipidaemia', 'triglycerides', 'type 2 diabetes', 'clinical trials.' Main articles published in English between 2000 and 2017 were reviewed and included. The author also requested information regarding clinical trials and preclinical studies with pemafibrate from Kowa Company, Ltd., Japan.

\section{New thinking: the rationale for SPPARMs}

PPARs are nuclear hormone receptors which bind to DNA as a heterodimer with the Retinoid X Receptor (RXR), and together they recognise specific DNA sequences in and around target genes referred to as PPAR response elements (PPREs). There are three different types of PPARs, $a, \beta$ and $\gamma$ [30]. PPAR $\alpha$ is abundantly expressed in highly active metabolic tissues such as the liver, kidney, heart, muscle, brown adipose tissue, as well as the vascular wall (smooth muscle cells, endothelial cells and macrophages). In contrast, PPAR $\gamma$ is predominantly expressed in white and brown adipocytes, 
macrophages and the large intestine, and PPAR $\beta$ in virtually all tissues and cell types [23, 30, 31].

When activated by the binding of either an endogenous ligand or synthetic PPAR agonist (such as a fibrate for PPAR $\alpha$ ), heterodimerisation with a ligand-activated RXR results in a conformational change, leading to the transrepression or transactivation of target genes. During transrepression, the activated PPAR binds to cytokineactivated transcription factors, such as nuclear factor kappa B or activator protein-1, and blocks the interaction between the activated transcription factors and the promoter region of the target gene, thereby preventing transcription and, in this example, reducing inflammation. In contrast, during transactivation, the activated PPAR binds to PPRE upstream of the target gene, and with the involvement of cofactors, renders the PPAR complex 'transcriptionally active' [23, 29, 32-35]. A large number of genes carry response elements for PPARs.

The focus of interest in this review, PPARa, plays a key role in metabolic homeostasis, regulating lipid metabolism, specifically HDL synthesis and metabolism, and VLDL turnover, by controlling the expression of key targets including apo A-I, A-II, A-V and C-III, lipoprotein lipase (LPL), scavenger receptor B1 (SR-B1), the ATPbinding cassette transporters $A B C A 1$ and $A B C G 1$, and acyl CoA synthetase $[23,35,36]$. There is also evidence to suggest that pharmacological PPAR $\alpha$ activation may be involved in regulation of glucose homeostasis (although the underlying mechanisms in humans are unclear), as well as reduction in inflammation and thrombogenesis, and improvement of vascular function [23, 34-36]. Thus, activation of PPARa results in attenuation of abnormal lipid and/or glucose metabolism, and is also protective against atherothrombosis by down-regulating inflammatory genes of monocytes and macrophages [23, 32, 33]. PPAR $\alpha$ is therefore at the cross-roads of obesity, diabetes and CVD, and thus a logical target for therapeutic intervention. In contrast, PPAR $\gamma$ targets include genes involved in obesity and insulin resistance, and thus regulates adipogenesis and glucose homeostasis.

PPARs possess a large lipid-binding pocket capable of encompassing a range of endogenous ligands. On binding, each ligand triggers a unique conformational change,leading to differential pattern of coactivator recruitment, which in turn results in specific tissue- and gene-selective effects. It is important to note that while PPAR ligands may share cofactors leading to a shared biological response, there are also differences in cofactor selectivity, resulting in differing responses (Fig. 1). Thus, modulating the receptor-cofactor binding profile of the PPAR ligand offers the opportunity to improve desirable biological effects (via transactivation of desirable target genes), and limit known adverse effects (via transrepression of undesirable genes) of the PPAR ligand. This concept underlies the rationale for the development of SPPARMs which differentially induce a unique receptorcofactor binding profile conferring improved efficacy and avoidance of unwanted side effects [37].
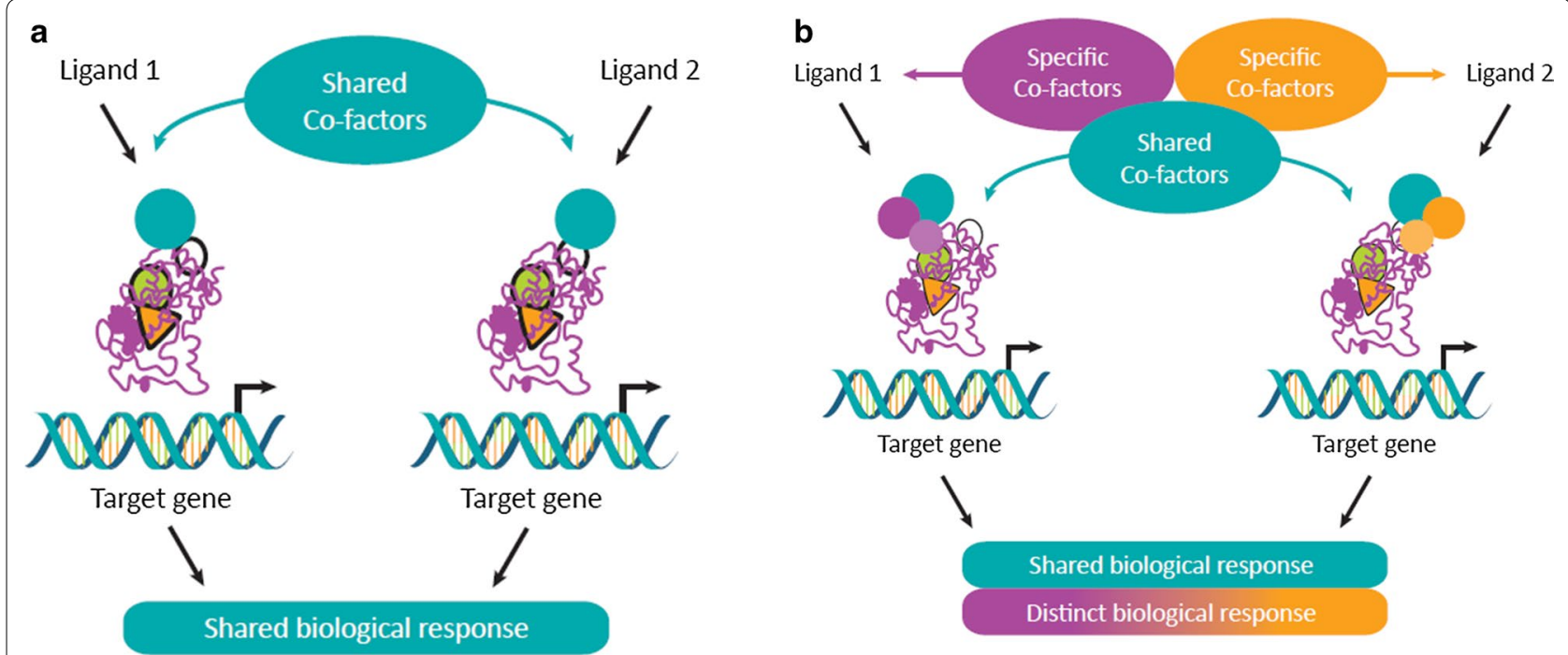

Fig. 1 Schematic representation showing how selective nuclear receptor modulation underpins the SPPARM concept. The binding of different ligands to nuclear receptors induces different conformational changes which influence cofactor affinity. Different ligands may share cofactors, resulting in shared biological responses (a) but may also have distinct differences in the cofactor-receptor binding profile (b). Thus, the unique receptor-cofactor binding profile of the ligand is the key determinant of the specificity and potency of receptor binding and in turn modulates gene- and tissue selective effects 
The SPPARM concept has already been applied to PPAR $\gamma$. The first such SPPARMYs, INT131 and MK0533, have been shown in preclinical studies to exhibit at least comparable antidiabetic effects to pioglitazone but with an improved adverse event profile [23, 38, 39]. The SPPARM concept has also been recognized for PPAR $\alpha$. Indeed, there was early evidence for this as regulation of human apoA-I by gemfibrozil and fenofibrate was mediated by selective modulation of PPAR $\alpha$ [40]. From the clinical perspective, the development of a novel SPPARM $\alpha$ with increased selectivity, high potency, as well as an improved safety profile compared with current PPAR $\alpha$ agonists offers advantages in patients with atherogenic dyslipidaemia.

\section{A novel SPPARMa: pemafibrate (K-877)}

Pemafibrate (K-877, Parmodia $\left.{ }^{\mathrm{TM}}\right)$ was identified as an agonist with very high potency and selectivity against human PPAR $\alpha$ as a result of screening based on the SPPARM $\alpha$ concept. Pemafibrate differed from other PPAR $\alpha$ agonists currently available, which were developed without definitive knowledge of their specific mechanism of action. Structurally, pemafibrate (K-877) has an acidic region as in other PPAR $\alpha$ agonists, but with the addition of unique benzoxazole and phenoxyalkyl side-chains, resulting in greatly enhanced PPAR $\alpha$ activity and selectivity [41] (Fig. 2). In cell-based transactivation assays, pemafibrate was shown to be $>2500$-fold more potent than fenofibric acid, the active metabolite of fenofibrate, for human PPAR $\alpha$ with $>5000$-fold greater activity for PPAR $\alpha$ than either PPAR $\gamma$ or $\delta$ [42].

Some characteristics of the gene transactivation profile for pemafibrate suggest that it is not just a PPARa agonist but a SPPARMa agent. Comprehensive transcriptome analysis showed that 11 of the top 20 genes up-regulated by pemafibrate were involved in carbohydrate and lipid metabolism, as for fenofibric acid. Key target genes such as $V L D L R$ and $A B C A 1$ were induced to a greater extent by pemafibrate than fenofibric acid, but pemafibrate had no effect on peroxisome biogenesis genes in human hepatocytes [43]. Pemafibrate also rescued interferon $\gamma$-induced suppression of nuclear receptor co-repressor 1 and 2 (NCoR1 and NCoR2), co-repressors of proinflammatory cytokines, in macrophages, and suppressed

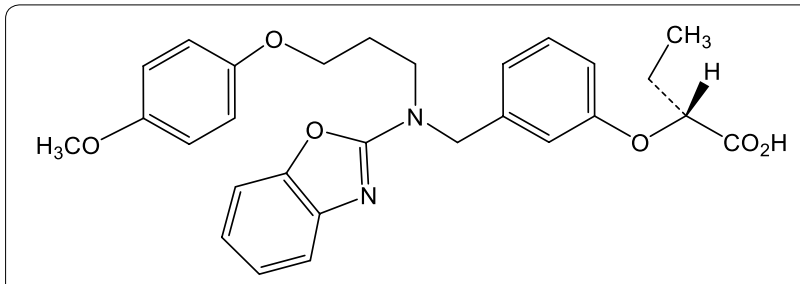

Fig. 2 Structure of pemafibrate (K-877) pro-inflammatory mediators, including vascular cell adhesion molecule 1 (VCAM-1) and monocyte chemoattractant protein-1 (MCP-1) in endothelial cells. Antiinflammatory effects were observed in human umbilical vein endothelial cells with pemafibrate $0.1 \mu \mathrm{M}$ whereas fenofibrate at concentrations up to $10 \mu \mathrm{M}$ had no effect $[44,45]$.

Other important differences were evident. Pemafibrate (but not fenofibric acid) upregulated the genes encoding mannose-binding lectin $2(M B L 2)$, involved in regulation of the innate immune system, inflammation and, possibly, vascular complications in diabetes [46, 47], as well as glutamyl aminopeptidase (ENPEP), involved in regulation of blood pressure [48], in transcriptome analysis [43]. In addition, pemafibrate induced expression of fibroblast growth factor 21 ( $F G F 21$ ) to a greater extent than fenofibric acid [43]. FGF21 has been implicated in the regulation of glucose, lipid and energy homeostasis in man, although findings are conflicting [49, 50]. There may also be a plausible biological link with nonalcoholic fatty liver disease (NAFLD), given that FGF21 decreases TGs, improves insulin sensitivity and counters obesity by suppressing weight gain, the major risk factor for NAFLD $[49,51]$. These findings implicate a cooperative mechanism, possibly involving the combination of PPAR $\alpha$, cyclic AMP responsive element-binding protein (CREBH), and 3-hydroxy-3-methylglutaryl-CoA synthase 2 (HMGCS2), in regulation of FGF21 [52, 53]. Taken together, in vitro evidence for pemafibrate showed enhanced potency and selectivity for PPAR $\alpha$, suggesting added potential for management of dyslipidaemia.

\section{Preclinical data}

Preclinical studies have established the pharmacological profile of pemafibrate, showing enhanced TG lowering and elevation in HDL-C levels compared with fenofibrate. In a rat model of hypertriglyceridaemia, the effect of pemafibrate $3 \mathrm{mg} / \mathrm{kg}$ on TG lowering was significantly greater (by about 2-fold) compared with fenofibrate (300 $\mathrm{mg} / \mathrm{kg}$ ), and was also accompanied by a greater increase in plasma levels of FGF21 (Data presented at the 80th European Atherosclerosis Society Congress. May 25-28, 2012. Milan, Italy, personal communication from Kowa Company, $L t d$ ). In vitro studies using liver samples from Zucker Fatty rats showed that pemafibrate reduced de novo synthesis of TGs and cholesterol, and increased beta-oxidation. Sprague-Dawley rats dosed with pemafibrate showed inhibition of VLDL secretion and accelerated TG clearance via LPL activation [42]. Additionally, in C57BL/6J mice fed a Western diet, pemafibrate attenuated fasting and postprandial hypertriglyceridaemia, as well as accumulation of remnant lipoproteins, by enhancing LPL activity and reducing weight gain [54]. 
Administration of pemafibrate to transgenic apoE2 mice led to more pronounced HDL-C elevation at a 100fold lower dose than fenofibrate $(1 \mathrm{mg} / \mathrm{kg}$ versus $100 \mathrm{mg} /$ kg) [Data presented at the 80th European Atherosclerosis Society Congress. May 25-28, 2012. Milan, Italy, personal communication from Kowa Company, Ltd]. Pemafibrate promoted macrophage cholesterol efflux to HDL in vitro, resulting in inhibition of lipid deposition in the aorta and reduction in the aortic atherosclerotic lesion burden in Western diet-fed apoE2KI mice compared with control; in contrast, the effect with fenofibrate was not statistically significant (Fig. 3) [55]. There was also evidence that the potent anti-inflammatory effects of pemafibrate observed in vitro translated to attenuation of atherosclerotic lesion development after mechanical injury in another animal model $[44,45,55]$.

In summary, preclinical data show that pemafibrate modulated gene expression mediated by PPAR $\alpha$, which in turn led to improved beneficial effects on atherogenic dyslipidaemia, inflammation and atherosclerosis, when compared with current PPAR $\alpha$ agonists. There was also evidence to suggest the possibility of novel targets, notably FGF21.

\section{Clinical trials}

Pemafibrate is being investigated in a comprehensive clinical trial programme, initially in Japan and latterly in Europe/USA, as both monotherapy and add-on to statin therapy. To date, over 2300 patients, the majority with dyslipidaemia and over one-quarter with concomitant type 2 diabetes mellitus, have been studied [Data on file, Kowa Company, Ltd.]. Key published trials are summarised in Table 2. Pemafibrate has been approved for the treatment of dyslipidaemia in Japan (July, 2017), and is currently in Phase III development in Europe/USA.

\section{Efficacy \\ Lipid effects}

Clinical studies have confirmed the efficacy of pemafibrate in patients with atherogenic dyslipidaemia, either as monotherapy or as add-on to statin treatment (Table 1). In a dose-ranging phase II study in patients with elevated TGs ( $\geq 200 \mathrm{mg} / \mathrm{dL}$ or $2.3 \mathrm{mmol} / \mathrm{L}$ ) and low HDL-C $(<50 \mathrm{mg} / \mathrm{dL}$ in men or $<55 \mathrm{mg} / \mathrm{dL}$ in women $)$ [56], treatment with pemafibrate $(0.05-0.4 \mathrm{mg}$ daily for 12 weeks), resulted in dose-dependent reduction in TGs (by up to $43 \%$ at $0.2-0.4 \mathrm{mg} /$ day) and an increase in HDL-C (by up to $21 \%$ at $0.4 \mathrm{mg} /$ day). These lipid-modifying effects were significant compared with placebo but although numerically larger, did not differ significantly from those observed with micronized fenofibrate capsules $100 \mathrm{mg} /$ day (Table 1, Fig. 4). Lipoprotein analysis showed that the increase in HDL-C levels with pemafibrate was attributable to significant increases in the three smaller subpopulations of HDL (medium, small, and very small HDL). Treatment with pemafibrate was also associated with a significant decrease versus placebo in nonHDL-C (by up to $12 \%$ at a dose of $0.1 \mathrm{mg}$ twice daily), as
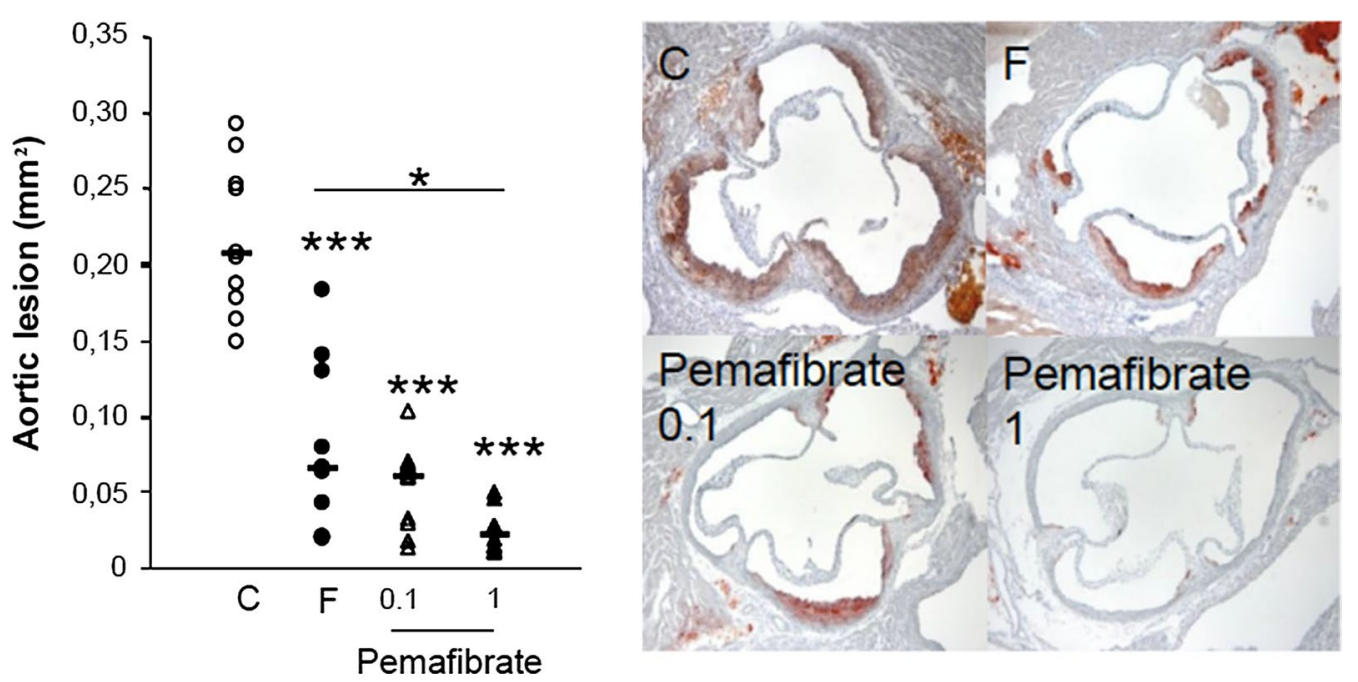

Fig. 3 Anti-atherogenic effects of pemafibrate (K-877) in apolipoprotein E transgenic mice. ApoE2KI mice were fed a Western diet and treated with pemafibrate ( 0.1 or $1 \mathrm{mg} / \mathrm{kg}$ ), fenofibrate $(250 \mathrm{mg} / \mathrm{kg}$ ) or control (carboxy methyl cellulose) daily and were sacrificed after 10 weeks. The left panel shows significant reduction in the atherosclerotic lesion area in mice dosed with pemafibrate $0.1 \mathrm{mg} / \mathrm{kg}$ compared with control. This effect was enhanced in the pemafibrate $1 \mathrm{mg} / \mathrm{kg}$ group. Each symbol represents the average area staining in the aortic sinus of individual animals and the bar represents the median of the values ( $n=10$ per group). ${ }^{*} p<0.05,{ }^{* *} p<0.001$ versus control. Representative photomicrographs showing Oil-red-O stained fatty-streaks in the atherosclerotic lesions is shown on the right panel. Reproduced with permission from Hennuyer et al. [55] 
Table 1 Summary efficacy data from published Phase II trials with pemafibrate

\begin{tabular}{|c|c|c|c|c|c|c|}
\hline Citation no. & Patients & $\mathrm{N}$ & Dose (mg/day) & Weeks & Mean $\Delta$ in TG (\%) & Mean $\Delta$ in HDL-C (\%) \\
\hline \multicolumn{7}{|l|}{ Monotherapy } \\
\hline \multirow[t]{8}{*}[56]{} & \multirow[t]{8}{*}{ Japanese patients with atherogenic dyslipidaemia ${ }^{a}$} & \multirow[t]{8}{*}{224} & Pemafibrate & \multirow[t]{8}{*}{12} & & \\
\hline & & & 0.05 & & $\downarrow 30.9 \pm 6.9^{* * *}$ & $\uparrow 11.9 \pm 2.8^{* * *}$ \\
\hline & & & 0.1 & & $\downarrow 36.4 \pm 6.6^{* * *}$ & $\uparrow 16.5 \pm 2.7^{* * *}$ \\
\hline & & & 0.2 & & $\downarrow 42.6 \pm 6.7^{* * *}$ & $\uparrow 16.3 \pm 2.8^{* * *}$ \\
\hline & & & 0.4 & & $\downarrow 42.7 \pm 6.7^{* * *}$ & $\uparrow 21.0 \pm 2.8^{* * *}$ \\
\hline & & & Fenofibrate & & & \\
\hline & & & 100 & & $\downarrow 29.7 \pm 6.7$ & $\uparrow 14.3 \pm 2.8$ \\
\hline & & & Placebo & & $\uparrow 28.5 \pm 6.8$ & $\downarrow 2.3 \pm 2.8$ \\
\hline \multirow[t]{8}{*}[63]{} & \multirow[t]{8}{*}{ Japanese patients with atherogenic dyslipidaemia ${ }^{a}$} & \multirow[t]{8}{*}{526} & Pemafibrate & \multirow[t]{8}{*}{12} & & \multirow[t]{8}{*}{$\uparrow 20.3-24.7$} \\
\hline & & & 0.1 & & $\downarrow 46.3^{* * *}$ & \\
\hline & & & 0.2 & & $\downarrow 46.7^{* * *}$ & \\
\hline & & & 0.4 & & $\downarrow 51.8^{* * *}$ & \\
\hline & & & Fenofibrate & & & \\
\hline & & & 100 & & $\downarrow 38.3^{* * *}$ & \\
\hline & & & 200 & & $\downarrow 51.5^{* * *}$ & \\
\hline & & & Placebo & & $\downarrow 2.7$ & \\
\hline \multicolumn{7}{|c|}{ Add-on to statin } \\
\hline \multirow[t]{4}{*}[60]{} & \multirow[t]{4}{*}{ Japanese patients with TG $\geq 2.3 \mathrm{mmol} / \mathrm{L}$} & \multirow[t]{4}{*}{423} & Pemafibrate & \multirow[t]{4}{*}{24} & & \\
\hline & & & 0.2 & & $\downarrow 46.8 \pm 2.6^{* * *}$ & $\uparrow 17.6 \pm 17.2^{* * *}$ \\
\hline & & & $0.2 / 0.4^{c}$ & & $\downarrow 50.8 \pm 2.5^{* * *}$ & $\uparrow 16.3 \pm 14.6^{* * *}$ \\
\hline & & & Placebo & & $\downarrow 0.8 \pm 3.0$ & $\uparrow 4.4 \pm 12.7$ \\
\hline \multirow[t]{5}{*}[60]{} & \multirow{5}{*}{$\begin{array}{l}\text { Add-on to pitavastatin Japanese patients with TG } \\
\geq 2.3 \mathrm{mmol} / \mathrm{L}, \text { non-HDL-C } \geq 3.9 \mathrm{mmol} / \mathrm{L}\end{array}$} & \multirow[t]{5}{*}{188} & Pemafibrate & \multirow[t]{5}{*}{12} & & \\
\hline & & & 0.1 & & $\downarrow 46.1 \pm 3.9^{* * *}$ & $\uparrow 13.6 \pm 15.4^{* *}$ \\
\hline & & & 0.2 & & $\downarrow 53.4 \pm 3.8^{* * *}$ & $\uparrow 19.7 \pm 19.4^{* * *}$ \\
\hline & & & 0.4 & & $\downarrow 52.0 \pm 3.9^{* * *}$ & $\uparrow 12.7 \pm 19.3^{*}$ \\
\hline & & & Placebo & & $\downarrow 6.9 \pm 4.0$ & $\uparrow 3.4 \pm 12.5$ \\
\hline \multirow[t]{4}{*}{ [59] } & \multirow{4}{*}{$\begin{array}{l}\text { T2DM and dyslipidemia Japanese patients with TG } \geq 1.7 \\
\text { and }<11.3 \mathrm{mmol} / \mathrm{L}\end{array}$} & \multirow[t]{4}{*}{167} & Pemafibrate & \multirow[t]{4}{*}{24} & & \\
\hline & & & 0.2 & & $\downarrow 44.3^{* * *}$ & \\
\hline & & & 0.4 & & $\downarrow 45.1^{* * *}$ & \\
\hline & & & Placebo & & $\downarrow 10.8^{* * *}$ & \\
\hline [61] & $\begin{array}{l}\text { Caucasian patients, controlled LDL-C and atherogenic } \\
\text { dyslipidaemia }^{b}\end{array}$ & 408 & $\begin{array}{l}\text { Pemafibrate } \\
0.1,0.2 \text { or } 0.4\end{array}$ & 12 & $\downarrow 34.0-54.4^{* * *}$ & $\uparrow 7.4-12.9^{* * *}$ \\
\hline [62] & $\begin{array}{l}\text { Caucasian type } 2 \text { diabetes patients with controlled LDL-C } \\
\text { and atherogenic dyslipidaemia }{ }^{\mathrm{b}}\end{array}$ & $161^{d}$ & $\begin{array}{l}\text { Pemafibrate } \\
0.1,0.2 \text { or } 0.4\end{array}$ & 12 & $\downarrow 44.7-67.4^{* * *}$ & NR \\
\hline
\end{tabular}

HDL-C high-density lipoprotein cholesterol, LDL-C low-density lipoprotein cholesterol, TG triglycerides, T2DM type 2 diabetes mellitus

** $p<0.01$, *** $p<0.001$ versus control

a $\mathrm{TG} \geq 2.3 \mathrm{mmol} / \mathrm{L}(200 \mathrm{mg} / \mathrm{dL})$ and low HDL-C

b TG 1.9-5.7 mmol/L (175-500 mg/dL) and low HDL-C

For both a and b, low HDL-C was defined as $<1.3 \mathrm{mmol} / \mathrm{L}(50 \mathrm{mg} / \mathrm{dL})$ in men or $<1.4 \mathrm{mmol} / \mathrm{L}(55 \mathrm{mg} / \mathrm{dL})$ in women

c Patients with TG $\geq 1.7 \mathrm{mmol} / \mathrm{L}(150 \mathrm{mg} / \mathrm{dL}$ ) at week 8 were uptitrated to $0.4 \mathrm{mg} /$ day from week 12

d Subgroup analysis of Kastelein et al. [61]

well as lipid parameters closely related to TGs, including VLDL-cholesterol (up to 48\%), remnant-cholesterol (up to $50 \%$ ), apoB (up to $9 \%$ ), apoB48 (up to $56 \%$ ) and apoCIII (up to 35\%). At the highest doses (0.2 and $0.4 \mathrm{mg} /$ day), reduction in VLDL-cholesterol was significantly greater than with fenofibrate $100 \mathrm{mg} /$ day ( 44 and $48 \%$, versus
26\%, respectively) (Table 2) [56]. While there was a slight increase in LDL-C levels (by $5.0-8.9 \%$ ), apoB and nonHDL-C levels both significantly decreased. Lipoprotein analysis indicated that only large and medium LDL fractions increased during treatment with pemafibrate. There were also dose-dependent increases in apoAI and apoAII 


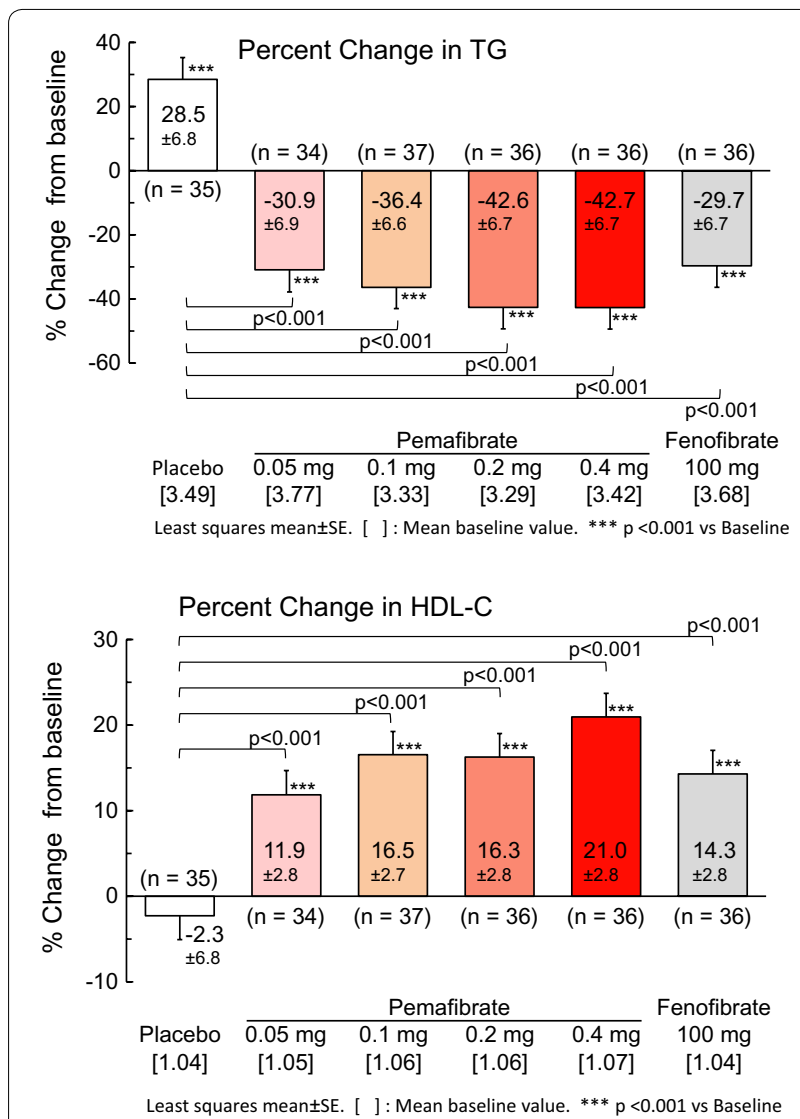

Fig. 4 Least squares mean percent change in triglycerides (TG; top panel) and high-density lipoprotein cholesterol (HDL-C) (bottom panel) after 12 weeks treatment with pemafibrate $(0.05,0.1,0.2$ or $0.4 \mathrm{mg} /$ day), fenofibrate (100 mg/day) or placebo in patients with elevated TG ( $\geq 200 \mathrm{mg} / \mathrm{dL}$ or $2.3 \mathrm{mmol} / \mathrm{L}$ ) and low HDL-C (Adapted from Ishibashi et al. [56]) (by $9 \%$ and $30 \%$, respectively with pemafibrate $0.2 \mathrm{mg}$ twice daily versus 6 and 20\% with fenofibrate $100 \mathrm{mg} /$ day) [56].

The TG-lowering effects of pemafibrate were confirmed in combined analysis of Phase II/III studies in 750 patients with elevated TGs $(\geq 200 \mathrm{mg} / \mathrm{dL}$ or $2.3 \mathrm{mmol} / \mathrm{L})$. Daily doses of pemafibrate $(0.1,0.2$ or $0.4 \mathrm{mg})$ resulted in significantly greater reduction in TGs than fenofibrate $100 \mathrm{mg} /$ day (by $45-52 \%$ versus $38 \%, \mathrm{p}<0.01$ ), although the response was similar to fenofibrate $200 \mathrm{mg}$ daily (decrease by 51\%) [57]. Taken together, these findings suggest that pemafibrate has the potential to improve both lipoprotein quality and quantity.

\section{Non-lipid effects}

Interestingly, a clinical pharmacology study in patients with dyslipidaemia showed that pemafibrate $0.4 \mathrm{mg} /$ day increased hepatic glucose uptake, as evaluated by the hyperinsulinaemic-euglycaemic clamp procedure [58]. These findings suggest that pemafibrate may have the potential to ameliorate hepatic insulin sensitivity. Results from Phase II/III trials were also encouraging. In the dose-ranging Phase II study described above [56], treatment with pemafibrate $0.2 \mathrm{mg} /$ day reduced fasting plasma glucose and homeostatic model assessment of insulin resistance (HOMA-IR). Added to this, in a combined analysis of Phase II/III studies including 676 patients with dyslipidaemia, treatment with pemafibrate resulted in significant improvement in fasting plasma glucose, fasting plasma insulin, and HOMA-IR [Data presented at the 50th European Association for the Study of Diabetes, September 15-19, 2014. Vienna, Austria,

Table 2 Effects of pemafibrate on atherogenic apolipoproteinB-containing lipoproteins in a phase II dose-ranging study Adapted from Ishibashi et al. [56].

\begin{tabular}{|c|c|c|c|c|c|c|}
\hline \multirow[t]{2}{*}{ Parameter } & \multirow[t]{2}{*}{ Placebo, $(\mathbf{n}=35)$} & \multicolumn{4}{|c|}{ Pemafibrate (K-877) mg/day } & \multirow{2}{*}{$\begin{array}{l}\text { Fenofibrate } \mathrm{mg} / \mathrm{day} \\
100(\mathrm{n}=36)\end{array}$} \\
\hline & & $0.05(n=34)$ & $0.1(n=37)$ & $0.2(n=36)$ & $0.4(n=36)$ & \\
\hline Total C & $0.1 \pm 9.8$ & $-2.7 \pm 11.4$ & $-6.5 \pm 11.9^{* * \dagger}$ & $-7.0 \pm 11.3^{* * * \dagger}$ & $-5.3 \pm 12.9^{*}$ & $-6.0 \pm 11.8^{* \dagger \dagger}$ \\
\hline Non-HDL-C & $0.7 \pm 12.8$ & $-5.8 \pm 12.4^{*}$ & $-11.8 \pm 14.0^{* * *+\dagger+}$ & $-12.2 \pm 13.8^{* * *+\dagger}$ & $-10.5 \pm 14.2^{* * *+\dagger+}$ & $-10.1 \pm 14.2^{* * *+\dagger}$ \\
\hline VLDL-C ${ }^{a}$ & $13.3 \pm 38.9$ & $-24.3 \pm 24.0^{* * *+\dagger \dagger}$ & $-37.3 \pm 26.7^{* * *+\dagger+}$ & $-43.8 \pm 24.0^{* * *+\dagger \dagger}$ & $-48.4 \pm 27.5^{* * *+十 \dagger}$ & $-25.8 \pm 29.7^{* * *+\dagger}$ \\
\hline$L D L-C^{a}$ & $-6.3 \pm 16.2^{*}$ & $8.9 \pm 21.3^{* \dagger}$ & $8.3 \pm 29.4^{\dagger}$ & $5.0 \pm 28.0$ & $7.4 \pm 26.5^{\dagger}$ & $5.3 \pm 23.4^{\dagger}$ \\
\hline Remnant C & $38.7 \pm 75.7^{* *}$ & $-32.3 \pm 33.8^{* * *+\dagger \dagger}$ & $-42.8 \pm 29.4^{* * *+\dagger \dagger}$ & $-48.3 \pm 28.1^{* * *+\dagger \dagger}$ & $-50.1 \pm 31.8^{* * *+\dagger+}$ & $-31.8 \pm 35.0^{* * *+\dagger}$ \\
\hline ApoB & $-2.0 \pm 9.9$ & $-1.4 \pm 13.6$ & $-8.9 \pm 13.6^{* * * \dagger}$ & $-7.8 \pm 15.0^{* *}$ & $-8.1 \pm 11.6^{* * *}$ & $-5.7 \pm 14.4^{*}$ \\
\hline ApoB48 & $54.6 \pm 171.1$ & $-28.4 \pm 43.1^{* * *+\dagger+}$ & $-43.1 \pm 47.1^{* * *+\dagger}$ & $-55.9 \pm 25.6^{* * *+\dagger}$ & $-51.2 \pm 29.3^{* * *+\dagger+}$ & $-37.9 \pm 42.9^{* * *+\dagger}$ \\
\hline ApoCIII & $7.9 \pm 27.4$ & $-22.2 \pm 14.4^{* * *+\dagger+}$ & $-29.0 \pm 18.9^{* * *+\dagger \dagger}$ & $-34.6 \pm 17.7^{* * *+\dagger+}$ & $-33.4 \pm 19.2^{* * *+\dagger \dagger}$ & $-27.2 \pm 18.9^{* * *+\dagger+}$ \\
\hline
\end{tabular}

Data are given as mean \pm standard deviation (SD) for the percent change from baseline to week 12

Apo apolipoprotein, $C$ cholesterol, $H D L$ high-density lipoprotein, $L D L$ low-density lipoprotein, VLDL very low-density lipoprotein

Significantly different from baseline (week 0 ) ${ }^{*} p<0.05$, ${ }^{* *} p<0.01,{ }^{* * *} p<0.001$

Significantly different from placebo ${ }^{\dagger} p<0.05,{ }^{+\dagger} p<0.01,{ }^{+t \dagger} p<0.001$

Figures in italics: significantly different from fenofibrate $p<0.01$

a Measured by ultracentrifugation 
personal communication from Kowa Company Ltd.]. Similar findings have been reported in type 2 diabetes patients with dyslipidaemia [59].

Furthermore, there were significant increases in plasma levels of FGF21 after treatment with pemafibrate 0.1$0.4 \mathrm{mg} /$ day for 12 weeks compared with placebo, whereas no effect was observed with fenofibrate $100 \mathrm{mg} /$ day [56, 58]. Taken together, these findings suggest that pemafibrate may have important non-lipid effects, consistent with the pharmacological profile of pemafibrate as a SPPARM $\alpha$, as shown in vitro and in preclinical studies.

\section{Add-on to statin}

As add-on to statin therapy in 423 Japanese patients with hypertriglyceridaemia (> $200 \mathrm{mg} / \mathrm{dL}$ or $2.3 \mathrm{mmol} / \mathrm{L}$ ), pemafibrate $0.2 \mathrm{mg} /$ day reduced TGs by $47 \%$ (versus $0.8 \%$ with placebo) (Table 1 ). Uptitration to $0.4 \mathrm{mg} /$ day in patients with TGs $\geq 150 \mathrm{mg} / \mathrm{dL}(1.7 \mathrm{mmol} / \mathrm{L})$ at 8 weeks led to a higher proportion of patients attaining the desirable TG level (fasting TGs $<150 \mathrm{mg} / \mathrm{dL}$ or $1.7 \mathrm{mmol} / \mathrm{L}$ ) at week 24 (36.2\% versus 29.7\%) [60]. A similar response was observed with pemafibrate added to pitavastatin therapy in 188 Japanese patients with hypertriglyceridaemia [60] (Table 1). At the highest dose (0.4 mg/day), there was also significant improvement in fasting blood glucose and HOMA-IR ( $\mathrm{p}<0.01$ and $\mathrm{p}<0.05$, respectively) [60].

Pemafibrate $(0.1-0.4 \mathrm{mg} /$ day $)$ was investigated in a large Phase II study in Europe in patients with atherogenic dyslipidaemia despite well controlled LDL-C levels on stable statin therapy [61]. At the highest dose $(0.4 \mathrm{mg} /$ day), TGs were reduced by $54 \%$, remnant-cholesterol (calculated as total cholesterol-LDL-C-HDL-C) by $58 \%$, and apoCIII by $36 \%$, and plasma HDL-C concentration was increased by $13 \%$. Post hoc analysis in patients with type 2 diabetes mellitus at baseline showed improved lipid-modifying efficacy with pemafibrate, with reduction in TGs by up to $67 \%$, remnant cholesterol by $82 \%$ and apoCIII by $40 \%$ [62].

Taken together, these studies show that pemafibrate $(0.2-0.4 \mathrm{mg} /$ day $)$ is effective in the management of hypertriglyceridaemia, with or without low plasma HDL-C concentration, either as monotherapy or against a background of stable statin therapy. There are encouraging data to suggest that pemafibrate improves glucose metabolism, which merits further study.

\section{Safety and tolerability}

Beyond efficacy, safety and tolerability are key considerations for any novel therapy. As already discussed, the SPPARM concept was extended to PPAR $\alpha$ in the search for an agent with improved potency and selectivity so as to overcome clinical concerns with the use of fibrates, specifically relating to adverse effects on liver and renal function. Evidence from the phase II/III study [63] showed that pemafibrate was well tolerated, with adverse event rates similar to or lower than those reported for placebo or fenofibrate. Notably, pemafibrate was associated with a lower rate of abnormal liver function tests compared with fenofibrate; only one patient discontinued due to this event compared with 3 and 11 patients allocated fenofibrate $100 \mathrm{mg}$ and $200 \mathrm{mg}$, respectively.

Importantly, the available safety data show that treatment with pemafibrate does not appear to affect renal function parameters. In the integrated analysis of phase II/III Japanese studies, there was no change in estimated glomerular filtration rate (eGFR), whereas a significant decline in eGFR was observed with fenofibrate treatment over 12 weeks $(p<0.001)$ [57], consistent with previous findings from both the Fenofibrate Intervention and Event Lowering in Diabetes (FIELD) and ACCORD studies [64, 65]. In a phase II study in Europe [61, 62], minor effects on changes in serum creatinine observed over 12 weeks with pemafibrate were considered clinically negligible or not associated with treatment, even in patients with type 2 diabetes mellitus at baseline. A small increase in serum homocysteine levels (by $2.4 \mu \mathrm{mol} / \mathrm{L}$ ) was noted at a dose of $0.4 \mathrm{mg} /$ day compared with placebo, although the clinical relevance of this is indeterminate [61].

In conclusion, the available safety experience with pemafibrate is encouraging, with no clinically meaningful deleterious effects on renal or hepatic function. However, long-term data in real world practice are needed to fully evaluate the safety profile of this novel agent.

\section{Unanswered questions}

The available data show the benefits of applying the SPPARM concept to PPAR $\alpha$, showing effective lowering of TGs, as well as other atherogenic measures, notably VLDL- and remnant cholesterol, in statin-treated patients with atherogenic dyslipidaemia. The safety profile of pemafibrate appears promising, with no evidence of clinically meaningful adverse effects on renal or hepatic function during treatment for up to 24 weeks, thus reinforcing the value of improved selectivity with this SPPARM $\alpha$.

The key question, however, is whether this novel SPPARM $\alpha$ impacts the high residual risk of cardiovascular events that persists in statin-treated patients with atherogenic dyslipidaemia, especially those with concomitant type 2 diabetes mellitus. Both the FIELD and ACCORD Lipid trials have failed to provide definitive answers with the use of fenofibrate, largely due to methodological reasons. The FIELD trial was initiated before statin use was considered first-line for prevention of CVD; indeed, the study criteria excluded patients with an 
indication for lipid-lowering therapy. The study population was at low to moderate global CVD risk, $75 \%$ had no prior CVD and only about one-third of patients had the characteristic atherogenic dyslipidaemic profile associated with type 2 diabetes (i.e., low HDL-C and elevated triglycerides) [66]. While in ACCORD Lipid all patients received concomitant simvastatin treatment, and the study population was at higher cardiovascular risk than in FIELD (37\% had previous CVD), median triglycerides $(164 \mathrm{mg} / \mathrm{dL}$ or $1.8 \mathrm{mmol} / \mathrm{L})$ were below that indicated for definition of atherogenic dyslipidaemia [67].

To address these remaining uncertainties regarding PPAR $\alpha$-targeted agents, PROMINENT (Pemafibrate to Reduce cardiovascular OutcoMes by reducing triglycerides IN diabetic patiENTs) has been initiated. This study aims to recruit 10,000 patients with type 2 diabetes mellitus and elevated TGs $(\geq 200 \mathrm{mg} / \mathrm{dL}$ or $2.3 \mathrm{mmol} / \mathrm{L}$ and $<500 \mathrm{mg} / \mathrm{dL}(5.7 \mathrm{mmol} / \mathrm{L})$ and low HDL-C $(\leq 40 \mathrm{mg} / \mathrm{dL}$ or $1.0 \mathrm{mmol} / \mathrm{L}$ ), with and without established CVD [68]. Patients will be randomised to treatment with pemafibrate $0.4 \mathrm{mg} /$ day or placebo, against a background of aggressive, standard of care management of cardiovascular risk factors including treatment with high-intensity statins. The primary study endpoint is a composite of nonfatal myocardial infarction, nonfatal ischaemic stroke, hospitalisation for unstable angina requiring unplanned coronary revascularisation, or cardiovascular death [68]. Anticipating an average follow-up of 4 years, we can expect answers to this question by early 2022 .

Another area of potential therapeutic interest is in the management of non-alcoholic fatty liver disease (NAFLD). Already there are promising results from a phase II b trial with elafibranor (GFT-505), a PPAR- $\alpha$ / PPAR- $\delta$ agonist, that improving atherogenic dyslipidaemia and insulin resistance may have benefit in patients with non-alcoholic steatohepatitis (NASH) [69]. With a profile including reduction in TGs and remnant cholesterol, upregulation of FGF21, and the lack of clinically meaningful effects on hepatic function, pemafibrate may have a possible role in NAFLD, specifically NASH. Indeed, in animal studies, pemafibrate appeared to ameliorate diet-induced NASH [70], by modulation of lipid turnover and energy metabolism, as well as NAFLD induced by a methionine-choline-deficient diet, by increased expression of fatty acid $\beta$-oxidation genes [71].

Finally, potential benefits of pemafibrate on microvascular complications of type 2 diabetes, notably diabetic retinopathy, previously reported for fenofibrate [72, 73], merit investigation. While the pathogenesis of diabetic retinopathy is still incompletely understood, evidence suggests a role for diabetes-induced down-regulation of PPAR $\alpha$ [74], as well as the involvement of inflammatory pathways, especially in obese individuals [75]. A nested study of PROMINENT will investigate this issue. Studies in $d b / d b$ mice also showed that pemafibrate inhibited the diacylglycerol-protein kinase $\mathrm{C}-\mathrm{NAD}(\mathrm{P}) \mathrm{H}$ oxidase pathway, resulting in suppression of lipid accumulation and oxidative stress in the kidney [76]. Thus, given the improved selectivity and potency of this SPPARM $\alpha$ agent, as well as evidence of anti-inflammatory effects, pemafibrate may offer potential for ameliorating this important, disabling diabetic microvascular complication.

\section{Conclusions}

Atherogenic dyslipidaemia, prevalent among patients with type 2 diabetes and obesity, is a contributor to lipidrelated residual cardiovascular risk. Accumulating evidence has led to renewed thinking about the importance of targeting this dyslipidaemia, in particular elevated TGs, to reduce this risk. Among current therapeutic options, fibrates are the logical option, but have relatively low potency and selectivity for PPAR $\alpha$. Extension of the SPPARM concept to PPAR $\alpha$ has led to the development of pemafibrate, which in preclinical studies, has shown improved potency and selectivity compared with currently available fibrates. In clinical trials, pemafibrate was effective in the management of atherogenic dyslipidaemia, either as monotherapy or add-on to statin treatment. There were no clinically meaningful adverse renal effects, including no elevation in serum creatinine, and no significant effects on hepatic function. Long-term data are needed, however, for definitive evaluation of the benefit versus risk of this novel SPPARM $\alpha$ for reduction of residual cardiovascular risk. Finally, investigation of a possible role for pemafibrate in the management of microvascular complications of diabetes, notably diabetic retinopathy, as well as in NAFLD, may be merited. A novel approach to addressing residual cardiovascular risk may be well within our grasp.

\footnotetext{
Abbreviations

ABCA1: ATP-binding cassette transporter ABCA1 (member 1 of human transporter sub-family ABCA); ABCG1: ATP-binding cassette sub-family G member 1; ACCORD: Action to Control Cardiovascular Risk in Diabetes; Apo: apolipoprotein; CREBH: cyclic AMP responsive element-binding protein; CVD: cardiovascular disease; eGFR: estimated glomerular filtration rate; ENPEP: glutamyl aminopeptidase; FGF21: fibroblast growth factor 21; FIELD: Fenofibrate Intervention and Event Lowering in Diabetes; FOURIER: Further Cardiovascular Outcomes Research With PCSK9 Inhibition in Subjects With Elevated Risk; HDL-C: high-density lipoprotein cholesterol; HMGCS2: 3-hydroxy-3-methylglutaryl-CoA synthetase 2; HOMA-IR: homeostatic model assessment of insulin resistance; IMPROVE-IT: Examining Outcomes in Subjects With Acute Coronary Syndrome: Vytorin (Ezetimibe/Simvastatin) vs Simvastatin; LDL-C: low-density lipoprotein cholesterol; LPL: lipoprotein lipase; MBL2: mannose-binding lectin 2; MCP-1: monocyte chemoattractant protein-1; NAFLD: non-alcoholic fatty liver disease; NASH: non-alcoholic steatohepatitis; NCoR1 and NCoR2: nuclear receptor co-repressors 1 and 2; PPARa: peroxisome proliferator-activated receptor alpha; PPRE: peroxisome proliferator-activated receptor response element; PROMINENT: Pemafibrate to Reduce cardiovascular OutcoMes by reducing triglycerides IN diabetic patiENTs; REVEAL: Randomized EValuation of
} 
the Effects of Anacetrapib Through Lipid-modification; RXR: retinoid X receptor; SPPARMa: selective PPARa modulator; SR-B1: scavenger receptor B1; TG: triglyceride; VCAM-1: vascular cell adhesion molecule 1; VLDL: very low-density lipoproteins.

\section{Acknowledgements}

Not applicable.

\section{Competing interests}

J-C Fruchart has received honoraria as a consultant for Kowa Company, Ltd. The R3i Foundation has received unrestricted grants for support of educational activities from Kowa Company, Ltd.

\section{Availability of data and materials}

The data that support the findings of this review are available from the corresponding author upon reasonable request.

\section{Consent for publication}

Permission for reproduction of figure 3 from Elsevier Ltd.

\section{Ethics approval and consent to participate}

Not applicable.

\section{Funding}

There are no sources of funding for this paper.

\section{Publisher's Note}

Springer Nature remains neutral with regard to jurisdictional claims in published maps and institutional affiliations.

Received: 15 August 2017 Accepted: 21 September 2017

Published online: 04 October 2017

\section{References}

1. World Health Organization. Geneva: WHO; 2017. Top 10 causes of death. http://www.who.int/mediacentre/factsheets/fs310/en/index2.html. Accessed 11 July 2017.

2. The Global Burden of Metabolic Risk Factors for Chronic Diseases Collaboration. Cardiovascular disease, chronic kidney disease, and diabetes mortality burden of cardiometabolic risk factors from 1980 to 2010: a comparative risk assessment. Lancet Diabetes Endocrinol. 2014;2:634-47.

3. Adair LS, Gordon-Larsen P, Du SF, Zhang B, Popkin BM. The emergence of cardiometabolic disease risk in Chinese children and adults: consequences of changes in diet, physical activity and obesity. Obes Rev. 2014;15(Suppl 1):49-59.

4. IDF Atlas 7th edn. International Diabetes Federation, Belgium, Brussels. 2015. http://www.diabetesatlas.org/resources/2015-atlas.html. Accessed 11 July 2017.

5. The global economic burden of Non-communicable Diseases. World Economic Forum, Harvard School of Public Health, Boston, USA. 2011. http://www3.weforum.org/docs/WEF_Harvard_HE_GlobalEconomicBurdenNonCommunicableDiseases_2011.pdf. Accessed 11 July 2017.

6. Stone NJ, Robinson JG, Lichtenstein AH, Bairey Merz CN, Blum CB, Eckel $\mathrm{RH}$, et al. $2013 \mathrm{ACC} / \mathrm{AHA}$ guideline on the treatment of blood cholesterol to reduce atherosclerotic cardiovascular risk in adults: a report of the American College of Cardiology/American Heart Association Task Force on Practice Guidelines. J Am Coll Cardiol. 2014;63(25 Pt B):2889-934.

7. Catapano AL, Graham I, De Backer G, Wiklund O, Chapman MJ, Drexel H, et al. 2016 ESC/EAS guidelines for the management of dyslipidaemias. Eur Heart J. 2016;37:2999-3058.

8. Cholesterol Treatment Trialists' (CTT) Collaboration, Fulcher J, O'Connell R, Voysey M, Emberson J, Blackwell L, Mihaylova B, et al. Efficacy and safety of LDL-lowering therapy among men and women: meta-analysis of individual data from 174,000 participants in 27 randomised trials. Lancet. 2015;385:1397-405
9. Cannon CP, Blazing MA, Giugliano RP, McCagg A, White JA, Theroux P, et al, IMPROVE-IT Investigators. Ezetimibe added to statin therapy after acute coronary syndromes. N Engl J Med. 2015;372:2387-97.

10. Sabatine MS, Giugliano RP, Keech AC, Honarpour N, Wiviott SD, Murphy SA, et al, FOURIER Steering Committee and Investigators. Evolocumab and clinical outcomes in patients with cardiovascular disease. N Engl J Med. 2017:376:1713-22

11. Fruchart JC, Davignon J, Hermans MP, Al-Rubeaan K, Amarenco P, Assmann G, et al. Residual risk reduction initiative (R3i). Residual macrovascular risk in 2013: what have we learned? Cardiovasc Diabetol. 2013:2014(13):26

12. Reiner Ž, De Bacquer D, Kotseva K, Prugger C, De Backer G, Wood D, EUROASPIRE III Study Group. Treatment potential for dyslipidaemia management in patients with coronary heart disease across Europe: findings from the EUROASPIRE III survey. Atherosclerosis. 2013;231:300-7.

13. Valensi P, Avignon A, Sultan A, Chanu B, Nguyen MT, Cosson E. Atherogenic dyslipidemia and risk of silent coronary artery disease in asymptomatic patients with type 2 diabetes: a cross-sectional study. Cardiovasc Diabetol. 2016;15(1):104.

14. Barter PJ, Caulfield M, Eriksson M, Grundy SM, Kastelein JJ, Komajda M, et al. Effects of torcetrapib in patients at high risk for coronary events. N Engl J Med. 2007;357:2109-22.

15. Schwartz GG, Olsson AG, Abt M, Ballantyne CM, Barter PJ, Brumm J, et al. Effects of dalcetrapib in patients with a recent acute coronary syndrome. N Engl J Med. 2012;367:2089-99.

16. Lincoff AM, Nicholls SJ, Riesmeyer JS, Barter PJ, Brewer HB, Fox KAA, et al. Evacetrapib and cardiovascular outcomes in high-risk vascular disease. N Engl J Med. 2017:376:1933-42.

17. HPS3/TIMI55-REVEAL Collaborative Group. Effects of anacetrapib in patients with atherosclerotic vascular disease. N Engl J Med. 2017. doi:10.1056/NEJMoa1706444

18. Varbo A, Benn M, Tybjærg-Hansen A, Jørgensen AB, Frikke-Schmidt R, Nordestgaard BG. Remnant cholesterol as a causal risk factor for ischemic heart disease. J Am Coll Cardiol. 2013;61:427-36.

19. Varbo A, Benn M, Tybjærg-Hansen A, Nordestgaard BG. Elevated remnant cholesterol causes both low-grade inflammation and ischemic heart disease, whereas elevated low-density lipoprotein cholesterol causes ischemic heart disease without inflammation. Circulation. 2013;128:1298-309.

20. Varbo A, Benn M, Smith GD, Timpson NJ, Tybjaerg-Hansen A, Nordestgaard BG. Remnant cholesterol, low-density lipoprotein cholesterol, and blood pressure as mediators from obesity to ischemic heart disease. Circ Res. 2015;116:665-73.

21. Fox CS, Hill Golden S, Anderson C, Bray GA, Burke LE, de Boer IH, et al. Update on prevention of cardiovascular disease in adults with type 2 diabetes mellitus in light of recent evidence: a Scientific Statement from the American Heart Association and the American Diabetes Association. Diabetes Care. 2015;38:1777-803.

22. Hegele RA, Ginsberg HN, Chapman MJ, Nordestgaard BG, Kuivenhoven $J A$, Averna $M$, et al. The polygenic nature of hypertriglyceridaemia: implications for definition, diagnosis, and management. Lancet Diabetes Endocrinol. 2014;2:655-66.

23. Gross B, Pawlak M, Lefebvre P, Staels B. PPARs in obesity-induced T2DM, dyslipidaemia and NAFLD. Nat Rev Endocrinol. 2017;13:36-49.

24. Wang D, Liu B, Tao W, Hao Z, Liu M. Fibrates for secondary prevention of cardiovascular disease and stroke. Cochrane Database Syst Rev. 2015;10:CD009580

25. Jakob T, Nordmann AJ, Schandelmaier S, Ferreira-González I, Briel M. Fibrates for primary prevention of cardiovascular disease events. Cochrane Database Syst Rev. 2016;11:CD009753.

26. Sacks FM, Carey VJ, Fruchart JC. Combination lipid therapy in type 2 diabetes. N Engl J Med. 2010;363:692-4.

27. Elam MB, Ginsberg HN, Lovato LC, Corson M, Largay J, Leiter LA, et al, Association of fenofibrate therapy with long-term cardiovascular risk in statin-treated patients with type 2 diabetes. JAMA Cardiol. 2017:2:370-80

28. Arbel Y, Klempfner R, Erez A, Goldenberg I, Benzekry S, Shlomo N, et al. Bezafibrate for the treatment of dyslipidemia in patients with coronary artery disease: 20-year mortality follow-up of the BIP randomized control trial. Cardiovasc Diabetol. 2016;15:11. 
29. Ferri N, Corsini A, Sirtori C, Ruscica M. PPAR-a agonists are still on the rise: an update on clinical and experimental findings. Expert Opin Investig Drugs. 2017;26:593-602.

30. Staels B, Dallongeville J, Auwerx J, Schoonjans K, Leitersdorf E, Fruchart JC. Mechanism of action of fibrates on lipid and lipoprotein metabolism. Circulation. 1998;98:2088-93.

31. Staels B, Koenig W, Habib A, Merval R, Lebret M, Torra IP, et al. Activation of human aortic smooth-muscle cells is inhibited by PPARalpha but not by PPARgamma activators. Nature. 1998:393:790-3.

32. Fruchart JC, Duriez P, Staels B. Peroxisome proliferator-activated receptor-alpha activators regulate genes governing lipoprotein metabolism, vascular inflammation and atherosclerosis. Curr Opin Lipidol. 1999;10:245-57.

33. Delerive P, De Bosscher K, Besnard S, Vanden Berghe W, Peters JM, Gonzalez FJ, et al. Peroxisome proliferator-activated receptor alpha negatively regulates the vascular inflammatory gene response by negative cross-talk with transcription factors NF-kappaB and AP-1. J Biol Chem. 1999;274:32048-54

34. Kertsen S. Integrated physiology and systems biology of PPARa. Mol Metab. 2014;3:354-71

35. Fruchart JC. Peroxisome proliferator-activated receptor-alpha (PPARalpha): at the crossroads of obesity, diabetes and cardiovascular disease. Atherosclerosis. 2009;205:1-8.

36. Perreault L, Bergman BC, Hunerdosse DM, Howard DJ, Eckel RH. Fenofibrate administration does not affect muscle triglyceride concentration or insulin sensitivity in humans. Metabolism. 2011;60:1107-14.

37. Fruchart JC. Selective peroxisome proliferator-activated receptor a modulators (SPPARMa): the next generation of peroxisome proliferatoractivated receptor a-agonists. Cardiovasc Diabetol. 2013;12:82.

38. Higgins SL, dePaoli AM. Selective peroxisome proliferator-activated receptor gamma (PPARY) modulation as a strategy for safer therapeutic PPARY activation. Am J Clin Nutr. 2010;91:267S-72S.

39. Doshi LS, Brahma MK, Bahirat UA, Dixit AV, Nemmani KV. Discovery and development of selective PPAR gamma modulators as safe and effective antidiabetic agents. Expert Opin Investig Drugs. 2010;19:489-512.

40. Duez H, Lefebvre B, Poulain P, Torra IP, Percevault F, Luc G, et al. Regulation of human apoA-l by gemfibrozil and fenofibrate through selective peroxisome proliferator-activated receptor alpha modulation. Arterioscler Thromb Vasc Biol. 2005;25:585-91.

41. Yamazaki Y, Abe K, Toma T, Nishikawa M, Ozawa H, Okuda A, et al. Design and synthesis of highly potent and selective human peroxisome proliferator-activated receptor alpha agonists. Bioorg Med Chem Lett. 2007;17:4689-93.

42. Takizawa T, Inokuchi Y, Goto S, Yoshinaka Y, Abe K, Inoue K, et al. The mechanism of K-877, a highly potent and selective PPARalpha modulator, on regulation of synthesis, secretion and metabolism of triglycerides and cholesterol. Circulation. 2013;128:A12867 (abstract).

43. Raza-labal S, Tanaka T, Anai M, Inagaki T, Matsumura Y, Ikeda K, et al. Transcriptome analysis of K-877 (a novel selective PPARa Modulator (SPPARMa))-regulated genes in primary human hepatocytes and the mouse liver. J Atheroscler Thromb. 2015;22:754-72.

44. Iwata H, Murakami K, Ricchiuto P, Singh S, Mojcher AC, Libby P, et al. K-877, A novel PPAR-alpha selective agonist, suppresses macrophage activation and arterial lesion formation. Circulation. 2013;128:A16180 (abstract)

45. Iwata H, Murakami K, Ricchiuto P, Singh S, Libby P, Aikawa E, et al. The novel PPARa selective agonist K-877 suppresses pro-inflammatory pathways and experimental arterial lesion formation. Circ Res. 2014;115:e8693 (Abstract 24160)

46. Larvie M, Shoup T, Chang WC, Chigweshe L, Hartshorn K, White MR, et al. Mannose-binding lectin binds to amyloid $\beta$ protein and modulates inflammation. J Biomed Biotechnol. 2012;2012:929803.

47. Káplár M, Sweni S, Kulcsár J, Cogoi B, Esze R, Somodi S, et al. Mannosebinding lectin levels and carotid intima-media thickness in type 2 diabetic patients. J Diabetes Res. 2016;2016:8132925.

48. Marc Y, Llorens-Cortes $C$. The role of the brain renin-angiotensin system in hypertension: implications for new treatment. Prog Neurobiol. 2011:95:89-103.

49. Inagaki T. Research perspectives on the regulation and physiological functions of FGF21 and its association with NAFLD. Front Endocrinol. 2015;6:147.
50. Talukdar S, Zhou Y, Li D, Rossulek M, Dong J, Somayaji V, et al. A long-acting FGF21 molecule, PF-05231023, decreases body weight and improves lipid profile in non-human primates and type 2 diabetic subjects. Cell Metab. 2016;23:427-40.

51. Kharitonenkov A, DiMarchi R. FGF21 revolutions: recent advances illuminating FGF21 biology and medicinal properties. Trends Endocrinol Metab. 2015;26:608-17.

52. Kim H, Mendez R, Zheng Z, Chang L, Cai J, Zhang R, et al. Liver-enriched transcription factor $C R E B H$ interacts with peroxisome proliferatoractivated receptor a to regulate metabolic hormone FGF21. Endocrinol. 2014;155:769-82

53. Vilà-Brau A, De Sousa-Coelho AL, Mayordomo C, Haro D, Marrero PF. Human HMGCS2 regulates mitochondrial fatty acid oxidation and FGF21 expression in HepG2 cell line. J Biol Chem. 2011;286:20423-30.

54. Masuda D, Kobayashi T, Nakaoka H, Kawase R, Nakatani K, Koseki M, et al. A novel potent and selective PPARalpha agonist, K-877, ameriolates the atherogenic profile of fasting and postprandial hypertriglyceridemia in mice. J Atheroscler Thromb. 2017 (in press).

55. Hennuyer N, Duplan I, Paquet C, Vanhoutte J, Woitrain E, Touche V, et al. The novel selective PPARa modulator (SPPARMa) pemafibrate improves dyslipidemia, enhances reverse cholesterol transport and decreases inflammation and atherosclerosis. Atherosclerosis. 2016;249:200-8.

56. Ishibashi S, Yamashita S, Arai H, Araki E, Yokote K, Suganami H, et al. Effects of K-877, a novel selective PPARa modulator (SPPARMa), in dyslipidaemic patients: a randomized, double blind, active- and placebo-controlled, phase 2 trial. Atherosclerosis. 2016;249:36-43.

57. Arai H, Ishibashi S, Yamashita S, Araki E, Yokote K, Kodama T. The novel highly potent and specific peroxisome proliferator-activated receptor alpha agonist K-877 improved liver enzymes and lipid profile without adversely affecting renal functions; integrated analysis of phase 2 and phase 2/3 double blind clinical trials. Circulation. 2013;128:A13118 (abstract)

58. Matsuba I, Matsuba R, Ishibashi S, Yamashita S, Arai H, Yokote K, et al. The effects of a selective PPARa modulator (SPPARMa), K-877 on insulin sensitivity evaluated by glucose clamp method. J Diabetes Investig. (in press).

59. Araki E, Yamashita S, Arai H, Yokote K, Sato J, Inoguchi T, et al. The effects of a selective PPARa modulator (SPPARMa), K-877 on glucose metabolism in type 2 diabetic patients with dyslipidemia. Diabetes Care. (in press)

60. Arai H, Ishibashi S, Yamashita S, Yokote K, Araki E, Suganami H, et al. Efficacy and safety of K-877, a novel selective peroxisome proliferatoractivated receptor a modulator (SPPARMa), in combination with statin treatment: two randomised, double-blind, placebo-controlled clinical trials in patients with dyslipidaemia. Atherosclerosis. 2017;261:144-52.

61. Kastelein JP, Senko Y, Hounslow N, Hovingh GK, Ginsberg HN. K-877, a selective PPAR alpha modulator (SPPARM alpha), ameliorates dyslipidaemia in patients with well-controlled LDL cholesterol levels on statin therapy, without increases in serum creatinine. Eur Heart J. 2015;36(Abstract Supplement):1048 (abstract).

62. Kastelein JJP, Senko Y, Hounslow N, Nojima T, Suganami H, Hovingh GK, et al. K-877, a selective PPAR alpha modulator (SPPARM alpha), improves dyslipidaemia in statin-treated patients with type 2 diabetes mellitus. Eur Heart J. 2015;36(Abstract Supplement):1048 (abstract).

63. Ishibashi S, Yamashita S, Arai H, Araki E, Yokote K, Kodama T. Efficacy and safety of K-877, a potent and selective PPAR-a agonist, in Japanese patients with dyslipidemia. Circulation. 2013;128:A10718 (Abstract).

64. Davis TM, Ting R, Best JD, Donoghoe MW, Drury PL, Sullivan DR, et al, Fenofibrate intervention and event lowering in diabetes study investigators. Effects of fenofibrate on renal function in patients with type 2 diabetes mellitus: the fenofibrate intervention and event lowering in diabetes (FIELD) study. Diabetologia. 2011;54:280-90.

65. Mychaleckyj JC, Craven T, Nayak U, Buse J, Crouse JR, Elam M, et al. Reversibility of fenofibrate therapy-induced renal function impairment in ACCORD type 2 diabetic participants. Diabetes Care. 2012;35:1008-14.

66. Scott R, Best J, Forder P, Taskinen MR, Simes J, Barter P, et al. Fenofibrate Intervention and Event Lowering in Diabetes (FIELD) study: baseline characteristics and short-term effects of fenofibrate [ISRCTN64783481]. Cardiovasc Diabetol. 2005;4:13.

67. Ginsberg HN. The action to control cardiovascular risk in diabetes (ACCORD) lipid trial: what we learn from subgroup analyses. Diabetes Care. 2011;34(Suppl 2):S107-8. 
68. ClinicalTrials.gov. US National Institutes of Health. Pemafibrate to Reduce Cardiovascular OutcoMes by Reducing Triglycerides IN patiENts With diabeTes (PROMINENT) (PROMINENT). ClinicalTrials. gov Identifier:NCT03071692. https://clinicaltrials.gov/ct2/show/ NCT03071692. Accessed 11 July 2017.

69. Ratziu V, Harrison SA, Francque S, Bedossa P, Lehert P, Serfaty L, et al, OLDEN-505 Investigator Study Group. Elafibranor, an agonist of the peroxisome proliferator-activated receptor- $a$ and $-\delta$, induces resolution of nonalcoholic steatohepatitis without fibrosis worsening. Gastroenterol. 2016;150:1147-59.

70. Takei K, Han SI, Murayama Y, Satoh A, Oikawa F, Ohno H, et al. The selective PPARa modulator K-877 efficiently activates the PPARa pathway and improves lipid metabolism in mice. J Diabetes Investig. 2017. doi:10.1111/ jdi.12621.

71. Honda Y, Kessoku T, Ogawa Y, Tomeno W, Imajo K, Fujita K, et al. Pemafibrate, a novel selective peroxisome proliferator-activated receptor alpha modulator, improves the pathogenesis in a rodent model of nonalcoholic steatohepatitis. Sci Rep. 2017;7:42477.
72. Keech AC, Mitchell P, Summanen PA, O'Day J, Davis TM, Moffitt MS, et al, FIELD study investigators. Effect of fenofibrate on the need for laser treatment for diabetic retinopathy (FIELD study): a randomised controlled trial. Lancet. 2007;370:1687-97.

73. ACCORD Study Group, ACCORD Eye Study Group, Chew EY, Ambrosius WT, Davis MD, Danis RP, Gangaputra S, Greven CM, et al. Effects of medical therapies on retinopathy progression in type 2 diabetes. N Engl J Med 2010;363:233-44.

74. Hu Y, Chen Y, Ding L, He X, Takahashi Y, Gao Y, et al. Pathogenic role of diabetes-induced PPAR-a down-regulation in microvascular dysfunction. Proc Natl Acad Sci USA. 2013;110:15401-6.

75. Sasongko MB, Wong TY, Jenkins AJ, Nguyen TT, Shaw JE, Wang JJ. Circulating markers of inflammation and endothelial function, and their relationship to diabetic retinopathy. Diabet Med. 2015;32:686-91.

76. Maki T, Maeda Y, Sonoda N, Makimura H, Kimura S, Maeno S, et al. Renoprotective effect of a novel selective PPARa modulator K-877 in db/db mice: a role of diacylglycerol-protein kinase C-NAD(P)H oxidase pathway. Metabolism. 2017;71:33-45.

\section{Submit your next manuscript to BioMed Central and we will help you at every step:}

- We accept pre-submission inquiries

- Our selector tool helps you to find the most relevant journal

- We provide round the clock customer support

- Convenient online submission

- Thorough peer review

- Inclusion in PubMed and all major indexing services

- Maximum visibility for your research

Submit your manuscript at www.biomedcentral.com/submit
() Biomed Central 